\title{
Raízes sociolingüísticas do analfabetismo no Brasil
}

\author{
The sociolinguistic roots of illiteracy in Brazil
}

\author{
Stella Maris BORTONI-RICARDO; \\ Maria da Guia Taveiro SILVA; \\ Maria do Rosário Rocha CAXANGÁ \\ Marli Vieira LINS
}

\section{RESUMO}

O analfabetismo é possivelmente o principal problema social brasileiro, que está na base de todos os demais. Na primeira parte deste estudo, fazemos uma análise sincrônica do analfabetismo, baseada no documento oficial Mapa do Analfabetismo. Na segunda parte procuramos identificar as raízes sócio-históricas do problema na história da colonização brasileira e na constituição do Brasil como nação, desde o século XIV, de uma perspectiva sociolingüística.

Palavras-chave: Analfabetismo no Brasil, matriz sociolingüística, a comunidade de fala de português no Brasil, dimensões sócio-históricas.

\begin{abstract}
Illiteracy is probably the major social problem in Brazil insofar as it underlies all the other ones. In the first part of this paper a synchronic analysis of the problem is presented based on official statistics put forward in the Map of Illiteracy. In the second part we look for the social historical roots of the problem in the Brazilian history, since the $16^{\text {th }}$ Century. Both analyses are sociolinguistically oriented.
\end{abstract}

Index Terms: Illiteracy in Brazil, the sociolinguistic matrix, the Brazilian speech community, historical dimensions. 


\section{Introdução}

O analfabetismo está na raiz de todos os grandes problemas sociais no Brasil. Constitui um mal radicado na sociedade brasileira, praticamente tão antigo quanto o próprio país, e infenso às diversas campanhas de alfabetização que surgem no bojo de políticas educacionais. Neste contexto, escrevemos este artigo que é produto de reflexões sobre as contribuições da Sociolingüística para uma política de alfabetização no Brasil. Discutimos o caráter perverso e persistente do analfabetismo brasileiro, situando-o numa matriz sócio-histórica e investigando suas causas na ecologia sociolingüística da comunidade de fala brasileira. Nesta primeira parte, levantamos informações censitárias que dão conta das dimensões e características do problema. Esses números nos mostram que a taxa de alfabetização no Brasil é uma das mais baixas do mundo, mesmo considerando apenas os países do Hemisfério Sul. No entanto, se comparamos o Brasil com outros países, verificamos que nosso país conta com dois fatores favoráveis à disseminação da cultura letrada: a língua de instrução na escola brasileira é o Português, que é justamente língua materna de mais de $90 \%$ da população nacional ${ }^{1}$. Essa é uma vantagem que poucos países em desenvolvimento têm, já que em sua maioria são multilíngües, o que torna difícil e onerosa a alfabetização dos alunos em sua língua materna. Outro fato que favorece a aprendizagem da leitura e escrita no Brasil é o caráter razoavelmente fonêmico do sistema ortográfico do português. Diferentemente do que acontece com o português, em muitas línguas a codificação ortográfica está longe de refletir a pronúncia vigente. Confrontando essas duas circunstâncias com os números do analfabetismo, coloca-se a pergunta: Por que o Brasil ainda não conseguiu alfabetizar a sua

\footnotetext{
${ }^{1}$ A constituição de 1988 garantiu aos povos indígenas brasileiros o direito a uma educação bilíngüe cujos códigos de instrução são a língua portuguesa e a língua materna da respectiva nação. Segundo Rodrigues (1986), são faladas no Brasil cerca de 170 línguas indígenas.
} 
população? Buscamos a resposta na matriz sociolingüística da comunidade de fala brasileira, cujas peculiaridades examinamos à luz dos processos sócio-históricos que a plasmaram.

\section{Alguns dados sobre a temática}

A partir do século XIX, a percentagem de analfabetismo (considerando como analfabeto o que não sabe ler e escrever; ou seja, no sentido censitário tradicional), começa a cair no Brasil. No entanto, até 1920, o índice de analfabetismo ainda superava 2/3 de sua população, o que equivalia a $64,9 \%$ das pessoas acima de quinze anos. Supõe-se que a taxa de analfabetismo entre as pessoas nessa faixa etária era de 77\% na época dos censos de 1872 e 1890 (nessas ocasiões os censos não especificaram idade para o levantamento do analfabetismo). Em 1920 calculava-se o analfabetismo em 65\%; trinta anos mais tarde, essa taxa caiu para 50\% e levou mais trinta anos para baixar para 25\%, em 1980 (FERRARO, 2004). Observe-se ainda a mudança no conceito de analfabetismo. Em 1958 a UNESCO definia como analfabeto um indivíduo que não consegue ler ou escrever algo simples. Duas décadas depois substituiu esse conceito pelo de analfabeto funcional, que é um individuo que, mesmo sabendo ler e escrever frases simples, não possui as habilidades necessárias para satisfazer as demandas do seu dia-a-dia e desenvolver-se pessoal e profissionalmente.

O Quinto Indicador Nacional de Alfabetismo Funcional (INAF), divulgado em setembro de 2005, pelo Instituto Paulo Montenegro - IPM - (Disponível em: < www.ipm.org.br>. Acesso em 26 de junho de 2006 e RIBEIRO, 2004), mostrou que só $26 \%$ dos brasileiros na faixa de 15 a 64 anos de idade são plenamente alfabetizados. Desses, $53 \%$ são mulheres, $47 \%$ são homens e $70 \%$, jovens de até 34 anos.

O censo de 2000 do IBGE (Instituto Brasileiro de Geografia e Estatística) considerou como analfabetos 10,6\% da população entre 15 e 64 anos, ou seja, 11.180.813 pessoas de um montante de 104.997.015. 
Em 2003, o índice de analfabetismo absoluto detectado pelo IPM, responsável pelas pesquisas que subsidiam o INAF, ficou em torno de $8 \%$ e são considerados em um nível rudimentar de alfabetismo cerca de 30\% dessa população. Dois anos mais tarde nova pesquisa do IPM registra uma queda de um ponto percentual no índice de analfabetismo. De acordo com os dados apresentados pelos censos demográficos do IBGE e outros sistemas avaliativos, percebemos que não houve quedas significativas, e sim, um movimento lento e gradual nos índices. É de se concluir portanto que as campanhas e programas governamentais destinados à erradicação do analfabetismo no país desde o final do século XX não têm dado conta de capacitar a população a ler e escrever, habilidades indispensáveis ao exercício da cidadania em uma sociedade cada vez mais letrada.

De 1920 até 1980, percebemos uma queda em termos percentuais, porém os números absolutos aumentaram de 11,4 milhões em 1920, para 18,7 milhões em 1980. Só depois dessa década os números do analfabetismo começam a apresentar leve diminuição, caindo em 2000 para 16,3 milhões, considerando sempre as pessoas com mais de quinze anos.

Segundo o Relatório de Desenvolvimento Humano de 2001 das Nações Unidas, 55\% dos países do mundo apresentam melhor desempenho na alfabetização que o Brasil. Na América Latina 72\% dos estados nacionais têm taxa de analfabetismo menor que a brasileira. As estatísticas internacionais mostram também que a posição relativa do Brasil no que concerne à taxa de analfabetismo não espelha a sua situação relativa em termos de renda per capita. Vejamos: apenas 34\% dos países no mundo e 28\% na América Latina têm renda per capita maior que a brasileira, mas a taxa brasileira de analfabetismo é mais de que o dobro da taxa típica exibida por países com a mesma renda per capita.

O analfabetismo é um problema histórico. Analisando-o nessa perspectiva, verificamos que ele apresenta características novas e velhas ao mesmo tempo. Trata-se de um problema relativamente novo porque só foi 
caracterizado como tal a partir do século XIX, e é também um problema velho porque, desde a sua origem, está relacionado a fatores sóciodemográficos, tais como: gênero, raça, localização geográfica, faixa etária, renda familiar e, principalmente, ao processo de urbanização.

Dados fidedignos sobre a questão estão agora disponíveis no Mapa do Analfabetismo no Brasil, que oferece um diagnóstico atualizado, reunindo dados demográficos, considerados nas suas diferentes dimensões. Trata-se de uma iniciativa do Inep (Instituto Nacional de Estudos e Pesquisas Educacionais Anísio Teixeira), que processou resultados do Censo Escolar do MEC, do IBGE e do PNUD (Programa de Desenvolvimento das Nações Unidas - United Nations Development Program - UNDP). As informações foram agrupadas para todos os municípios do país, considerada a divisão político-administrativa do ano de 2000, e permitem consulta individualizada.

Segundo o referido mapa, o número de analfabetos varia bastante de região para região. No Nordeste, o número de analfabetos é muito maior que nas regiões Sul e Sudeste. Na cidade de Guaribas no Piauí, por exemplo, a taxa de analfabetos chega a 59\%, enquanto que em Niterói, no estado do Rio de Janeiro, o índice de analfabetismo é apenas de 3.6\%. Há de fato uma forte correlação negativa entre índices de analfabetismo e o $\mathrm{IDH}^{2}$ de cada região.

Quanto à renda familiar, calculada em salários mínimos, ficou confirmado que quanto mais alta essa renda, mais acesso a família terá à

\footnotetext{
2 O IDH (Índice de Desenvolvimento Humano), desenvolvido pelo PNUD/ONU desde 1990, pretende ser uma medida geral, sintética, do desenvolvimento humano. Além de computar o PIB per capita, depois de corrigi-lo pelo poder de compra da moeda de cada país, o IDH também leva em conta dois outros componentes: a longevidade e a educação. Para aferir a longevidade, o indicador utiliza números de expectativa de vida ao nascer. O item educação é avaliado pelo índice de analfabetismo e pela taxa de matrícula em todos os níveis de ensino. A renda é mensurada pelo PIB per capita, em dólar PPC (paridade do poder de compra, que elimina as diferenças de custo de vida entre os países). Essas três dimensões têm a mesma importância no índice, que varia de zero a um. (Disponível em: < www.pnud.org.br/idh> $>$. Acesso em 26 de junho de 2006)
} 
alfabetização. $\mathrm{O}$ analfabetismo chega a ser 20 vezes maior nas famílias mais pobres. Nos domicílios com renda superior a dez salários mínimos, o índice é de apenas 1,4. Já naqueles cuja renda é inferior a um salário mínimo o índice alcança 29\%. A relação entre renda e alfabetização torna-se extremamente grave quando se leva em conta que o Brasil tem uma das piores taxas de distribuição de renda no mundo, perdendo apenas para Serra Leoa, na África. Em 2003, 1\% dos brasileiros mais ricos detinham uma renda equivalente aos ganhos dos 50\% mais pobres. (Disponível em: < www.ipea.gov.br/> . Acesso em 26 de junho de 2006). Políticas públicas de distribuição de renda nos últimos anos têm tentado corrigir essa distorção, mas os resultados obtidos ainda são modestos.

Em relação a gênero, foi observado que as mulheres apresentam uma taxa de alfabetização superior à dos homens. Esse resultado veio confirmar informações do INAF 2001 de que as mulheres se destacam mais que os homens nas questões que envolvem leitura e escrita.

Outra variável pesquisada pelo Inep em relação ao analfabetismo foi raça. Constatou-se que existem três vezes mais brancos alfabetizados do que negros e pardos, o que confirma importância do fator raça na desigualdade social no Brasil.

Mesmo não desconsiderando essas diferenças entre segmentos sociais, as pesquisas confirmam que o analfabetismo brasileiro não está restrito a nenhum grupo: ele é um mal que atinge crianças, jovens, adultos e, principalmente, idosos. Segundo os dados disponíveis, 7,4\% da população entre 10 e 19 anos é analfabeta, enquanto o índice de analfabetismo na faixa etária de 60 anos ou mais atinge a marca de 34\%.

Com relação à dicotomia rural x urbano no país, há que se observar que, no meio rural brasileiro, a taxa de analfabetismo é três vezes superior à da população urbana. A população rural apresenta um índice de analfabetismo de $28,7 \%$ e a urbana, de $9.5 \%$. Cabe aqui uma observação: é comum encontrarmos, na população radicada no campo, pessoas, mais 
freqüentemente homens, que não sabem ler e escrever e, no entanto, têm razoável habilidade para lidar com números e quantidades. As competências que demonstram em práticas sociais de letramento matemático, ou numeramento, são adquiridas nas rotinas de compra e venda de produtos agropecuários e em transações bancárias.

A simples constatação do percentual de analfabetos em áreas urbanas pode levar-nos à conclusão equivocada de que nessas regiões o analfabetismo seja problema social de pouca relevância. Não é bem assim. Há uma elevada parcela da população não-alfabetizada nas grandes cidades brasileiras. Em 125 municípios, de um total de 5.507, está um quarto dos analfabetos do país e 586 municípios respondem pela metade dos analfabetos da população com 15 anos ou mais. Entre os 100 municípios com o maior número de analfabetos estão 24 capitais. Na cidade de São Paulo, registram-se 383 mil e no Rio de Janeiro 199 mil. Essa concentração de analfabetos nas grandes cidades explica-se pelo alto contingente de migrantes que deixam as áreas rurais e demandam os centros urbanos, na busca por melhores condições de vida, indo radicar-se na periferia de cidades de médio e grande porte. Ali reproduzem e preservam muitos traços próprios de sua cultura pré-migratória, inclusive as características de sua linguagem. São populações que podem ser descritas como rurbanas (BORTONI-RICARDO, 1985).

Os dados relativos às taxas de analfabetismo nas áreas urbanas são indiciários de duas importantes dimensões na caracterização das raízes rurais da sociedade brasileira: o caráter rurbano dos grupos sociais que habitam a periferia das cidades, já mencionado, e as distorções na própria caracterização do que é área urbana e rural no país. Cientistas sociais, como o professor Eli da Veiga (2002) e seus associados têm mostrado que as estatísticas oficiais relativas à questão se ressentem de uma metodologia mais atualizada. 
Em seu livro “Cidades Imaginárias”, Eli da Veiga considera equivocados os critérios empregados pelo próprio IBGE. O equívoco na metodologia censitária tem origem em um decreto do Estado Novo de 1938, segundo o qual é área urbana toda sede de município ou distrito, independentemente do tamanho e das características das atividades produtivas de sua população. O autor argumenta que os parâmetros da OCDE (Organização de Cooperação e Desenvolvimento Econômico) são mais adequados que a metodologia oficial do IBGE. Segundo a OCDE, para um município ser considerado urbano, teria de apresentar uma densidade demográfica de 150 habitantes $/ \mathrm{km}^{2}$ e uma população nunca inferior a 50 mil habitantes. Se aplicados esses parâmetros, os 5.507 municípios brasileiros considerados urbanos passariam a 411 .

A análise dos números do analfabetismo que leva em conta as variáveis sociodemográficas, como renda e o IDH regional, entre outras, deixa patente que o Brasil tem o seu próprio apartheid (que o professor Cristovam Buarque denomina “apartação social”): de um lado a população cuja renda lhe faculta acesso aos bens de consumo, inclusive às práticas sociais de letramento e, de outro, as populações excluídas dessas práticas, cuja cultura é predominantemente oral.

A pesquisa "Retrato de Leitura no Brasil”, divulgada pela Revista Época em julho de 2001, de iniciativa da Câmara Brasileira do Livro (CBL), do Sindicato Nacional dos Editores de Livros (Snel), da Associação Brasileira de Editores de Livros (Abrelivros) e da Associação Brasileira de Celulose e Papel (Bracelpa), fez 5.503 entrevistas com pessoas de 14 anos ou mais, com pelo menos três anos de escolarização, em 40 cidades do país, que representam um universo estimado em 86 milhões de cidadãos. Os resultados mostraram que 62\% dos entrevistados - cerca de 53,3 milhões de pessoas - haviam lido livro no ano anterior. Esse percentual é mais alto no Brasil do que em Portugal. Mostrou também que apenas 20\% dos entrevistados haviam comprado os livros que leram; que $78 \%$ dos 
entrevistados apreciam os livros e que $89 \%$ vêem nele um meio de transmissão de idéias. Essa pesquisa deixou claro que o hábito da leitura está consolidado apenas numa parcela minoritária da população. Entre pessoas com curso superior ele é quase quatro vezes mais comum que entre os brasileiros cuja referência escolar se situa entre a 1a e a 4a série do ensino fundamental. Além disso, a familiaridade com a leitura é também um legado inter-geracional porque o hábito de leitura dos pais influencia a formação dos filhos como leitores.

Comprar livro é caro para boa parte da população. Um dos efeitos disso é a magreza das coleções particulares: ainda segundo a mesma pesquisa, $47 \%$ dos entrevistados têm no máximo dez livros em casa, e o número de exemplares que repousam sobre a estante de dois terços dos brasileiros não passa de 25. Além disso, o acesso gratuito ao livro é limitado. A rede pública de bibliotecas é calculada em menos de 5.000 unidades - menos de uma biblioteca por município, segundo números da Secretaria do Livro e da Leitura do Ministério da Cultura.

Dois estudos sociolingüísticos com populações rurbanas confirmam que a participação desses grupos em práticas sociais letradas é muito limitada. O primeiro foi conduzido em Brazlândia, no Distrito Federal, no início da década de 80 (BORTONI-RICARDO 1985; 2005). Em um grupo de 118 indivíduos de origem rural, dos quais 59\% tinham de zero a três anos de escolaridade, apenas 19\% declararam ler livros com freqüência, geralmente a Bíblia ou outros livros religiosos; 24\% lêem livros ocasionalmente e $47 \%$ nunca haviam lido um livro. Outro estudo mais recente (LOPES 2004), conduzido em uma comunidade de baixa renda na periferia de Teresina, mostrou que as atividades de leitura têm sempre uma dimensão instrumental naquela comunidade. Os membros do grupo só lêem textos portadores de informações necessárias à sua vida diária: contas de luz, passagens de ônibus, receitas médicas, placas comerciais, notas fiscais, 
etc. Alguns jovens mais competentes funcionam como escribas para escrever cartas e bilhetes familiares.

Para complementar esse levantamento sociodemográfico do analfabetismo no Brasil, convém observar que, não obstante suas altas taxas e seu lento declínio, dois fatores podem ser considerados como favorecedores da disseminação do letramento em nossa sociedade. Temos em mente o fato de mais de $99 \%$ da população brasileira ter como língua materna o português, que é também o veículo de instrução na escola no ensino fundamental (art. $210 \S 2^{\circ}$ da Constituição Federal de 1988), bem como também o caráter razoavelmente fonêmico da ortografia do português. Em 1953 a UNESCO reconheceu que a língua materna dos educandos é o melhor meio para a implementação de sua educação escolar, tanto do ponto de vista sociológico, quanto psicológico. No entanto, muitos países têm dificuldade de atingir esse desiderato em virtude do grande número de línguas e variedades presentes no repertório de suas populações. Prover cada criança com um programa de educação em sua língua materna é oneroso e de difícil operacionalização, em termos sociolingüísticos e políticos. Esse é o caso, por exemplo, da Índia com mais de 200 línguas e da Tanzânia com mais de 135 línguas (cf. FASOLD, 1984 e ZUENGLER, 1985). No Brasil, esse problema não assume uma dimensão nacional, restringindo-se a poucas comunidades.

O outro fato favorecedor do letramento a que nos referimos é ter sido a sistematização ortográfica do português sensível ao “apelo fonêmico”, tendência que MATTOSO CÂMARA (1977) atribui ao fonólogo português Gonçalves Viana, cujos trabalhos datam das últimas décadas do século XIX. Em línguas cuja ortografia- codificada há vários séculos- não passou por reformas, essa está longe de refletir a pronúncia vigente. É o caso do inglês, por exemplo. A seguinte anedota atribuída a Bernard Shaw (STUBBS, 1980) é bem ilustrativa da distância entre convenções ortográficas e a pronúncia contemporânea da língua inglesa. 
Para Shaw a palavra "fish” (peixe) poderia ser escrita "ghoti”, considerando que: $\mathrm{gh}=\mathrm{f}$, como em enough; $\mathrm{o}=\mathrm{i}$, como em women e, finalmente, $\mathrm{ti}=\mathrm{sh}$, como em nation. Na segunda parte desse estudo, a ser publicada em breve, vamos discutir em detalhes a relação entre a pronúncia contemporânea do português do Brasil e as convenções ortográficas da língua. Mas podemos adiantar que, nesse aspecto, levamos vantagem sobre muitas outras sociedades nacionais.

Essas duas vantagens que acabamos de descrever sucintamente não parecem estar contribuindo para a difusão universal das habilidades de letramento na nossa comunidade de fala. Por que isso acontece? Para buscar resposta a essa pergunta e para entendermos melhor por que alguns grupos sociais são mais afligidos pelo analfabetismo que outros, vamos procurar identificar as raízes desse mal na história externa da língua portuguesa no Brasil.

\section{Considerações finais}

A análise sociolingüística da comunidade de fala brasileira implica conhecimento da matriz sócio-histórica em que essa comunidade se criou e se plasmou. Para os objetivos deste artigo, vamos salientar alguns aspectos nessa matriz, entre os quais o caráter rural da sociedade brasileira até praticamente o século XX, o processo de urbanização, os fluxos migratórios nesse século e a contemporaneidade de estágios diversos de desenvolvimento.

A tradição sociológica brasileira é unânime em enfatizar a primazia da cultura rural no Brasil. Para BUARQUE DE HOLANDA (1997), no Brasil - Colônia e em outros países de história colonial recente, mal existiam tipos de estabelecimento humano intermediários entre os meios urbanos e as propriedades rurais; os primeiros, neste país, restritos à faixa litorânea e as 
últimas espalhando-se pelas regiões interioranas, à medida que as terras eram desbravadas e se sucediam os ciclos na produção agropecuária.

Desde o início da colonização, em março de 1549, quando Tomé de Souza, $1^{\circ}$ governador geral do Brasil, desembarca no arraial de Pereira, na Bahia de Todos os Santos, até o final do século XVII, prevaleceu na colônia um bilingüismo instável. Nessa fase de nossa história, conviviam o que veio a ser chamada de língua geral, língua originalmente falada pelos índios Tupinambá, que se difundiu na costa brasileira, do litoral de São Paulo ao litoral do nordeste ${ }^{3}$, e a língua portuguesa.(NARO e SCHERRE, 2007). Essa última chegava junto com os jesuítas, a elite administrativa e os aventureiros lusitanos que vinham à busca de enriquecimento rápido. A Língua Brasílica foi aos poucos cedendo lugar, no repertório dos indígenas, à interlíngua que eles empregavam no esforço para se comunicar com o elemento europeu. SILVA NETO (1977 p. 34-5) nos fornece um bom exemplo da interlíngua usada pelas populações nativas, que aprendiam de oitiva a língua do colonizador. Note-se ainda que os bandeirantes paulistas, até o século XVII, preservaram uma língua de origem tupi, que diferia um pouco da língua dos Tupinambá. Ao final do terceiro século de colonização, a língua dos Tupinambá já havia desaparecido da faixa litorânea, embora se tenha preservado em algumas localidades na bacia amazônica, onde é conhecida pelo nome de Nheengatú ${ }^{4}$. Os missionários da Companhia de Jesus, que se envolveram com a catequese e a instrução dos indígenas, ensinavam-lhes a língua portuguesa, mas também se esforçavam por aprender as línguas da terra, elaborando até mesmo gramáticas. O mais

\footnotetext{
${ }^{3}$ Segundo RODRIGUES (1986), a língua dos Tupinambá não foi chamada de "língua geral” nos dois primeiros séculos de colonização. José de Anchieta referiu-se a ela como "a língua mais usada na costa do Brasil". Outros autores a denominaram "língua do Brasil", "língua da terra" e "língua do mar". Após o século XVII consolidou-se a denominação "Língua Brasílica”, empregada em textos da época.

${ }^{4}$ A língua geral amazônica de hoje, Nheengatú ( "língua boa”) difere não só da língua Tupinambá, mas também da língua geral amazônica do século XVIII, o que se explica pelo longo lapso de tempo (cerca de 250 anos) entre o Tupinambá, que teve caráter de língua franca no início da colonização e o Nheengatú atual. RODRIGUES (1986).
} 
conhecido entre esses primeiros professores do Brasil foi o padre José de Anchieta, autor da "Primeira gramática da língua mais usada na costa do Brasil”, impressa em 1595 em Portugal, dois anos antes de sua morte (MIRANDA, 1966). Em 1759, o Marquês de Pombal expulsa a Companhia de Jesus de todo o território português, inclusive as colônias. Interrompe-se o trabalho nas escolas jesuíticas no Brasil e o incipiente esforço de escolarização da população local _ indígena, mestiça ou descendente de portugueses_ não é retomado senão mais de uma década depois, de forma bastante intermitente e irregular.

O ambiente de contato de línguas no Brasil - Colônia era ideal para desencadear mudanças rápidas na deriva da língua portuguesa, na ausência de uma política de educação, bem como de veículos da língua escrita, que têm efeito importante para coibir mudanças bruscas na deriva de uma língua.

De fato as condições sociolingüísticas nos primeiros séculos de colonização eram muito favoráveis à emergência de um pidgin de base portuguesa. Hoje em dia os lingüistas têm posições controversas quanto ao desenvolvimento de um pidgin nos primórdios da colonização brasileira. Argumentam alguns que ele não se teria formado, pois o seu curso natural seria evoluir para uma língua crioula, como nas outras colônias portuguesas, o que não aconteceu. Mas pode-se argumentar, contrariamente, que essa evolução tenha sido sustada pelo aumento do número de falantes do português a partir do século XVII, quando se descobriu ouro e pedras preciosas em Minas Gerais (BORTONI-RICARDO, 1985). Seja como for, o contato entre as línguas, a ausência de um sistema educacional e a ínfima circulação de textos escritos em português- já que até 1809 era proibida na Colônia qualquer atividade de imprensa- contribuíram para formar no Brasil uma variedade dialetal de português oral, muito distinta da língua falada e escrita em centros urbanos em Portugal e, posteriormente, no Brasil. Com pequenas diferenças regionais, essa variedade difundiu-se por todo o 
território brasileiro, com mais vitalidade nas grandes extensões rurais, pois nas cidades incipientes iria concorrer com o português lusitano, já em vias de padronização na sua modalidade escrita.

Se parece temerário conjeturar sobre a emergência de um pidgin no Brasil colonial, já que não há registros que o confirmem, pode-se afirmar, com razoável segurança, que o contato de vernáculos e o conseqüente surgimento de interlínguas entre os que aprendiam o português como língua estrangeira influenciaram a língua portuguesa falada pela massa colonial. Longe do efeito padronizador da cultura letrada, cultivada pelas instituições urbanas que são agentes letradores, a variedade da língua usada pelas populações rurais e interioranas era marcada por radical redução na morfologia flexional e por um léxico de forte influência tupi. Essa é a origem da língua e da cultura caipira, que veio a receber uma primeira descrição em 1920 com O dialeto caipira de Amadeu Amaral.

Não se pode esquecer que o multilingüismo da sociedade brasileira nos séculos XVI e XVII torna-se mais complexo com a chegada dos escravos africanos, que não eram portadores de língua e cultura homogêneas porque provinham de diferentes grupos étnicos: os Yoruba, chamados nagô; os Dahomey, denominados gegê e os Fanti - Ashanti, conhecidos como minas, além de outros grupos menores, conforme nos narra DARCY RIBEIRO (1995), baseado nos estudos pioneiros de Nina Rodrigues e Arthur Ramos. Como o tráfico negreiro durou cerca de três séculos, havia na sociedade colonial uma interação permanente entre escravos de diferentes gerações. Estima-se que cerca de três milhões e 300 mil escravos foram trazidos para o Brasil e aqui distribuídos pelas áreas de lavouras ou abrigados nas cidades, nas casas de família, como escravos domésticos. Esse grande contingente de africanos trazidos para o Brasil nunca teve oportunidade de aprender o português sistematicamente. As escolas, que já eram raras, não se abriam para os escravos, que ganharam a liberdade já quase ao final do século XIX, sem que, contudo, tivessem as condições de 
inserção no sistema de produção. Permaneceram à margem desse sistema, longe das escolas e da cultura letrada, e formaram os grandes contingentes de mão-de-obra barata e não-qualificada, mesmo depois que o país entrou, tardiamente, na era industrial.

A padronização do português brasileiro correu paralela ao processo de urbanização, ambos sujeitos a intermitências e, como observa RIBEIRO (1995), em relação à formação de nossas vilas e cidades, de natureza caótica. É bem verdade que já em 1770 o primeiro-ministro português, Marquês de Pombal, impôs uma gramática normativa única a todas as escolas de Portugal e de além-mar. Mas essa providência teve pouco efeito já que, como observamos, a massa populacional brasileira não tinha acesso a escola nem a práticas letradas, restritas ao clero e à elite que representava o estado português na colônia.

Verifica-se, então, que o apartheid brasileiro, que separa os que participam efetivamente da cultura letrada e os que estão à margem dessa cultura, como vimos até aqui, tem suas origens na organização social deste país desde o seu nascedouro.

Na Europa a industrialização precedeu a urbanização e há entre os dois processos uma relação de causa e conseqüência. No Brasil, como de resto nos países do terceiro mundo, a urbanização não foi conseqüência da industrialização e se explica por circunstâncias históricas e pressões econômicas que delas decorrem. Podem-se identificar dois períodos na urbanização brasileira (PEREIRA DE QUEIROZ, 1978). O primeiro tem início com a colonização, quando se criam os núcleos urbanos litorâneos do Brasil - Colônia. Salvador foi construída a partir de 1549, para abrigar a administração colonial; a fundação de Recife e Olinda está associada às invasões holandesas ainda no início do século XVI e a do Rio de Janeiro, às invasões francesas em 1565. Mas a população carioca só começa a adotar hábitos de sociedade burguesa quando a cidade se torna sede do reino português, em final de 1808, após a vinda da corte, que fugia ao ímpeto 
conquistador de Napoleão Bonaparte. Cerca de 30 anos mais tarde o modo burguês de vida chegaria a São Paulo que, no século seguinte, consolida-se como uma grande metrópole graças à cultura cafeeira. As primeiras cidades de Minas Gerais surgem com a exploração aurífera no início de século XVIII. O ouro e os diamantes financiaram suas igrejas, casario e toda a sua estrutura urbana.

À medida que o modo de vida burguês ganhava prestígio, aprofundava-se uma clivagem entre a cultura urbana e a cultura tradicional interiorana. As cidades se tornaram por excelência o locus da cultura de letramento, enquanto no interior se perpetuava uma cultura predominantemente oral. Segundo CÂNDIDO (1964), o modo de vida no campo preservou os elementos da cultura caipira, condicionados pelas suas origens nômades e pela sua economia de subsistência.

O processo de industrialização só começou no Brasil no final dos anos 40 do século XX. Inicia-se aí a segunda fase de urbanização. Segundo Pereira de Queiroz a ausência de uma base industrial nos séculos XIX e começo do século XX determinou que apenas algumas poucas cidades desenvolvessem um sistema social estratificado. Nas cidades menores e em regiões mais pobres foram mantidas a uniformidade e a tradição do modo rural de vida.

A difusão dos hábitos citadinos teve como conseqüência o aprofundamento da clivagem entre a cultura urbana, diretamente influenciada pelos modelos europeus, e a cultura rural, e levou as cidades a assumirem uma posição de superioridade em relação à vida interiorana. Nas décadas seguintes, algumas dessas áreas foram afetadas pela modernização, enquanto outras preservaram sua cultura tradicional. Para a autora, explicase assim a existência de duas sociedades paralelas no Brasil. Nas diferentes regiões essas duas sociedades paralelas vão consolidar-se em momentos distintos, o que resulta na contemporaneidade de estágios diversos de desenvolvimento. No século XX a urbanização brasileira acelerou-se, 
implementada pela introdução de tecnologia no campo, pelo massivo êxodo rural e melhorias nos sistemas de comunicação e de transporte, mas como já vimos, a população rural que se deslocou para as cidades recriou no novo habitat espaços culturais rurbanos. Sua efetiva integração ao modo urbano de vida é lenta e depende muito das oportunidades de acesso à escola e a práticas letradas.

Uma forma de se analisar a relação rural-urbano no Brasil, nas suas dimensões relacionadas ao letramento e ao repertório sociolingüístico das comunidades, é a postulação de um aparato metodológico onde se delineiam dois contínuos: de urbanização e de letramento (BORTONI-RICARDO, 2004, 2005). O primeiro vai das comunidades rurais mais isoladas até os centros cosmopolitas. Entre esses dois pólos, estende-se uma zona rurbana. Todo falante do português do Brasil situa-se em um ponto determinado desse contínuo, mas pode movimentar-se em direção a qualquer dos pólos, dependendo de sua rede de relações sociais, sua inserção em práticas sociais letradas e participação no sistema de produção, bem como seu gênero, faixa etária e outros componentes de sua identidade social. O contínuo de urbanização permite ainda distinguir regras variáveis graduais, presentes ao longo de todo o contínuo, e regras descontínuas, características do repertório das populações situadas no pólo rural e na zona rurbana. Já o contínuo de letramento é funcional para a classificação dos eventos interacionais como práticas sociais letradas ou de oralidade, considerando sempre as gradações possíveis entre esses dois pólos.

A análise sistemática da matriz sociolingüística do Português no Brasil, descrita sucintamente aqui, vai demonstrar que a heterogeneidade em nossa língua, cujas origens remontam às desigualdades sociais vigentes desde o período colonial, está diretamente relacionada ao acesso que os grupos sociais têm à cultura letrada e hegemônica, cultivada principalmente pelas elites urbanas. Não se pode implementar uma política nacional eficiente de alfabetização sem que se leve em conta a variação lingüística 
distribuída ao longo do contínuo de urbanização e estratificada em função de renda e status sócio-econômico, pois a língua padrão neste país é basicamente associada a classe social.

\section{Referências bibliográficas}

AMARAL, Amadeu. O dialeto caipira. São Paulo: HUCITEC, 1976.

BORTONI-RICARDO, Stella Maris. The urbanization of rural dialect speakers: a sociolinguistic study in Brazil. Cambridge: Cambridge University Press, 1985.

BORTONI-RICARDO, Stella Maris. Educação em língua materna: a sociolingüística na sala de aula. São Paulo: Parábola Editorial, 2004.

BORTONI-RICARDO, Stella Maris. Leitura e cultura: a contribuição da sociolingüística. in: Nós cheguemu na escola, e agora? Sociolingüística e Educação. São Paulo: Parábola Editorial, p.71-82, 2005.

BRASIL, Ministério da Educação/Inep. Mapa do analfabetismo no Brasil. Disponível em: <www.publicacoes.inep.gov.br/ >.

BUARQUE DE HOLANDA, Sérgio. Raízes do Brasil. São Paulo: Companhia das Letras, 1997.

CÂNDIDO, Antônio. Os parceiros do Rio Bonito. Rio de Janeiro: José Olympio,1964.

FASOLD, Ralph. The sociolinguistics of Society. Oxford: Basil Blackwell, 1984.

FERRARO, Alceu Ravanello. História quantitativa da alfabetização no Brasil. in RIBEIRO, V.M. (org.) p.195-207, 2004.

LOPES, Iveuta de Abreu. Cenas de letramentos sociais. Tese de doutorado. Universidade Federal de Pernambuco, 2004. 
MATTOSO CÂMARA JR., J. Para o estudo da fonêmica portuguesa. Rio de Janeiro: Padrão, 1977.

NARO, Anthony Julius e SCHERRE, Maria Marta P. Origens do português brasileiro. São Paulo: Parábola Editorial, 2007.

PEREIRA DE QUEIROZ, M.I. Cultura, sociedade rural, sociedade urbana no Brasil. Rio de Janeiro: Livros técnicos e científicos; São Paulo: EDUSP, 1978.

RIBEIRO, Vera Masagão (org.) Letramento no Brasil - Reflexões a partir do INAF 2001. São Paulo: Global, 2004.

RIBEIRO, Darcy. O povo brasileiro. São Paulo: Companhia das Letras, 1995.

RODRIGUES, Aryon Dall'Igna. Línguas brasileiras: para o conhecimento das línguas indígenas. São Paulo: Edições Loyola, 1986.

SILVA NETO, Serafim da. Introdução ao estudo da língua portuguesa no Brasil. Rio de Janeiro: Presença, 1977.

STUBBS, Michael. Language and Literacy: the sociolinguistics of reading and writing. Londres: Routledge \& Kegan Paul, 1980.

TAVARES de MIRANDA, Maria do Carmo. Educação no Brasil. Recife: UFPE, 1966.

VEIGA, J. E. da. Cidades imaginárias. Campinas: Autores Associados, 2002.

ZUENGLER, Jane. English, Swahili, or other languages? in: WOLFSON, Nessa e MANES, Joan (orgs.). Language of inequality. New York: Mouton, p. 241-254,1985. 


\section{Autoras:}

\section{Stella Maris Bortoni-Ricardo;}

Seguem os meus: Profa. Stella Maris Bortoni-Ricardo; Profa. Titular de Lingüística ( UnB); Mestra em Lingüística ( UnB); Doutora em Lingüística (Universidade de Lancaster); Estágio de Pós-doutorado (Universidade da Pennsylvania). Professora da Faculdade de Educação, UnB; Pesquisadora do CNPq. Informações sobre livros e artigos publicados em www.stellabortoni.com.br - sanae778@terra.com.br

\section{Maria da Guia Taveiro Silva;}

Mestra em educação (UnB); Doutoranda em Lingüística (UnB); Professora do departamento de letras da Universidade Estadual do Maranhão. Informações sobre publicações estão disponíveis no meu currículo lattes.

mariadaguiats@hotmail.com

\section{Maria do Rosário Rocha Caxangá}

Professora da Secretaria de Educação do Distrito Federal (SEEDF); Mestra em Educação (UnB); pesquisadora do LEF (Letramento no Ensino Fundamental - UnB).

rosariorrc@yahoo.com.br

\section{Marli Vieira Lins}

Formada em Letras (Universidade Católica de Brasília), Pedagoga (pela Universidade de Brasília), especialista em Docência do Ensino Superior (pela Universidade Candido Mendes), atualmente está terminando o mestrado em educação, discutindo a importância da oralidade no âmbito escolar (na UnB). É professora do curso de letras da Faculdade Evangélica de Brasília.

marlilins@pop.com.br

\section{Como citar este artigo:}

BORTONI-RICARDO, Stella Maris et al. Raízes sociolingüísticas do analfabetismo no Brasil. Revista ACOALFAplp: Acolhendo a Alfabetização nos Países de Língua portuguesa, São Paulo, ano 2, n. 4, 2008. Disponível em: <http://www.mocambras.org> e ou $<$ http://www.acoalfaplp.org>. Publicado em: março 2008. 